\title{
ECOLOGÍA Y ÉTICA DE LA LIBERACIÓN: UN DIÁLOGO DECISIVO PARA UNA ARQUITECTÓNICA DEFINITIVA
}

\author{
ENRIQUE TÉLLEZ FABIANI ${ }^{1}$
}

\begin{abstract}
RESUMEN: El diálogo sistemático que Dussel sostuvo con Apel (1989-1995) es uno de los momentos más importantes en la historia de la filosofía latinoamericana; no solo porque a nivel regional sitúa el pensamiento formulado desde el subcontinente como propio, original e innovador; sino, define con toda precisión una crítica a las categorías filosóficas más importantes que quedaron plasmadas en una "arquitectónica". Ésta trata de un orden metódico a través del cual debe ser discernida la realidad, con pretensión de universalidad y desde la criticidad que proveen las víctimas, como masas excluidas del planeta. En la primera parte, ponemos el acento en definir al interlocutor adecuado: el escéptico y el cínico, en la postura propia de las dos escuelas. En la segunda parte, resaltamos las limitaciones de la parte formal en detrimento de lo material. En la tercera y cuarta parte, ponemos énfasis en la verdad y la validez en la perspectiva ecológica. En la quinta, pasamos al "criterio universal de verdad", como discernimiento mínimo para efectuar la crítica ecológica adecuada. En la sexta parte, retomamos los criterios pero tratando de definir lo que la filosofía de la liberación entiende por "víctima". Finalmente, con formulaciones rápidas y sencillas, pero tratando de no ser reduccionistas, hablamos concretamente de la cuestión ecológica en concreto que deberá desarrollarse más ampliamente en un futuro.
\end{abstract}

PALABRAS CLABE: Dussel; Arquitectónica; Ecología; Ética.

ABSTRACT: The systematic dialogue that Dussel had with Apel (1989-1995) is one of the most important moments in the history of Latin American philosophy; not only because at the regional level it places the thought formulated from the subcontinent as its own, original and innovative; but, it defines with precision a critique of the most important philosophical categories that were embodied in an "architectural". This is a methodical order through which reality must be discerned, with a claim to universality and from the criticality provided by the victims, as masses excluded from the planet. In the first part, we emphasize defining the right interlocutor: the skeptic and the cynical, in the position of the two schools. In the second part, we highlight the limitations of the formal part to the detriment of the material. In the third and fourth part, we emphasize the truth and validity in the ecological perspective. In the fifth, we turn to the "universal criterion of truth", as a minimum discernment to make the appropriate ecological criticism. In the sixth part, we return to the criteria but trying to define what the philosophy of liberation means by "victim." Finally, with quick and simple formulations, but

\footnotetext{
${ }^{1}$ Es profesor de filosofía en la Universidad Nacional Autónoma de México y de física en la Universidad Iberoamericana. Obtuvo el doctorado en Estudios Latinoamericanos por la UNAM. Es miembro de varias asociaciones, como AFyL, AFM y CMPF.. E-mail: tellezfabiani@yahoo.com.
} 
trying not to be reductionists, we talk specifically about the ecological issue in particular that should be developed more broadly in the future.

KEYWORDS: Dussel; Architectonic; Ecology; Ethics.

En el último tercio del siglo XX, la filosofía de la liberación en Latinoamérica se caracterizó por proveer de justificación teórica a los movimientos de toda índole que procuraban la defensa de la dignidad humana. En este primer tercio del siglo XXI, vemos la necesidad de reforzar lo ganado, pero también de reorientar algunos preceptos hacia lo ecológico. Lo mismo la lucha de Berta Cáceres (Honduras), que la de la adolescente Greta Thumberg (Suecia), o Raoni Metuktire (Kayapó, Brasil), se han vuelto referentes de una revisión que se anuncia con urgencia. No nos debería de sorprender los cambios de una biosfera herida (incendios, inundaciones... fenómenos de una enfermedad mayor). Pero tampoco la confusión del escéptico negacionista, o la falta de voluntad para vivir del cínico con tendencia suicida; sino la inacción, la falta de voluntad práctica de una juventud desorientada y del conservadurismo de los mayores frente a la posibilidad, por primera vez real y cercana, de una catástrofe irreversible. Esto guía la preocupación del presente trabajo, aunque todavía de manera provisoria, dada la extensión del tema, la prontitud de la política y lo acotado de la propuesta.

La filosofía de la liberación es un pensamiento que en lugar de retraerse frente a la embestida ideológica, se reinventó constantemente hasta madurar con el sello característico del diálogo comprometido. Se trata de un grupo nutrido de pensadores que hacia finales de la década de los setenta del siglo XX vieron la necesidad de dialogar con diferentes actores para dar respuesta a las problemáticas concretas que se vivían entonces. Ahora se ha visto una necesidad de universalizar la teoría, rompiendo el regionalismo y con ello, rechazando cualquier reducción que se le atribuya. Enrique Dussel es quizá, el filósofo que ha elaborado con más sistematización y precisión el concepto de la liberación, con lo que se le ha caracterizado al quehacer cotidiano de esta escuela. Desde 1989 hasta 1995 mantuvo un diálogo con Karl-Otto Apel que estuvo lleno de detalles técnicos y argumentaciones de fundamentación filosófica. Se trata de la primera y definitiva reelaboración de las categorías clásicas de totalidad y exterioridad, pero además de distinciones que definieron su ética definitiva: la ética de la liberación. Este libro es una "respuesta a Apel", donde lo material y lo formal "son aspectos complementarios fundacionales de la razón ética”. (Mills, F. [2018], p. 92). Supone el intento más decidido de formular una ética mundial en la que actualiza el lenguaje y las categorías en estricto apego a las situaciones del momento. 
A partir de la publicación de su ética, en 1998, y asumiendo el diálogo con Apel, hacemos un comentario de posibles lecturas en torno a la ecología; ciertamente, sin agotar el tema y poniendo énfasis en la cuestión arquitectónica, a saber, una de las propuestas más significativas del pensamiento dusseliano. En mi opinión, la ecología no es un tema, de los muchos otros que se debaten como "aspectos" parciales de un todo, sino un concepto desde el cual se reconfigura todo el patrón vital que nos impone la naturaleza para continuar en su seno; se trata de las condiciones de posibilidad para insertarse en la trama de la vida.

Las primeras dos partes muestran la manera de colocarse (la ética del discurso apeliana y la filosofía de la liberación dusseliana) frente al escéptico y al cínico. La tercera parte nos sirve para establecer la distinción entre lo material y formal y su 'aplicación' a lo ecológico, cuya consecuencia inmediata, parte cuatro y cinco, es la distinción entre la verdad (material) y la validez (formal). En la sexta parte se hace énfasis en definir la 'víctima'. Finalmente, la síntesis que articulan las tres partes propuestas en la arquitectónica le dan sentido a lo que tratamos delinear como 'lo ecológico'.

\section{Los oponentes: el escéptico y el cínico}

Quizá no haya un punto nodal más importante en el pensamiento de Dussel como el diálogo que sostuvo con Apel, dado que le demandó explicaciones más detalladas y precisas; y, con ello, puso a prueba toda la herramienta intelectual de su parte. Además definió en gran medida lo que ahora conocemos bajo el apelativo de "arquitectónica". Dicho orden metodológico no nació en este diálogo, sino que tomó una forma definitiva que va a transformarse para definir la configuración última de la Política que hasta la fecha se encuentra en redacción. Se trata de recuperar en un sentido pleno la dialéctica, dado que la mayoría de los planteamientos filosóficos solo consideran uno de sus elementos, agotándose en discursos unilaterales, o reductivistas, donde los falsos dilemas académicos justifican, con el encubrimiento de una de las partes, la dominación. Por eso, el que piensa en lo cotidiano debe poner en crisis esa dominación, sutil o drástica, y transformarla. La "liberación" supone una interpretación con la complementaria y posible transformación.

En el III Seminario Internacional, de 1992, Dussel hace explícito algunos preceptos básicos sobre lo que será determinante para la filosofía de la liberación futura, enfrentándose (literalmente: situando al interlocutor frente a sí) a los dos oponentes de las dos escuelas filosóficas y contrastando sus posiciones. Se trata del problema de los oponentes; por un lado, el escéptico como el oponente de la ética del discurso; y, por otro, el cínico como el oponente de la filosofía de la liberación. Dados estos supuestos, se entiende que tanto sus arquitectónicas, 
como las estrategias argumentativas, son distintas. No obstante, la clave es descifrar la relación entre el escéptico y el cínico; y justo esta relación es el punto de partida porque al intentar una "fundamentación última" de parte de la ética del discurso, Apel muestra que ser radicalmente escéptico es caer necesariamente en una "contradicción performativa". Pero, por su parte, el enfrentamiento de la filosofía de la liberación se da cuando el cínico funda la moral del sistema vigente; dentro de cuya totalidad, el cínico gestiona la 'razón estratégica' con la fuerza irracional del poder, como dominación. De ahí, que se le denomine a partir de este momento, la "razón cínica".

El exceso de formalismo en la filosofía analítica ha soslayado cualquier "impureza" moral dentro de los argumentos; es el caso, justamente, de que Apel no acepte los argumentos de un Popper, por ejemplo, replicando que no debe sostenerse una idea logicista de la fundamentación. Por tanto, para Apel, el punto de partida debe ser un sujeto argumentante que reconoce implícitamente la "pretensión de validez" de todos los participantes de una comunidad de comunicación y cuyos argumentos pueden ser evaluados con argumentaciones racionales. Es decir, ninguna argumentación puede ser negada ni demostrada por medios coercitivos. La clave está en la incuestionabilidad: "la fundamentación filosófica última del principio de la ética reside justamente en la no-cuestionabilidad (reflexiva) del argumentar seriamente (y por lo tanto también del principio ético-normativo del discurso) por el argumentante, es decir, en cierta medida en el autocercioramiento reflexivo de la razón.” (Apel, [1999], 206 y ss.). Tampoco se trata de una contradicción tradicional porque si el escéptico participa en una comunidad de argumentación no puede negar, o dudar, la pretensión de validez en el mismo momento de argumentar contra toda argumentación posible; es decir, no puede usar la razón contra ella misma. En tanto figura retórica incluye al Otro, pero niega la validez de los posibles argumentos; en otras palabras, frente al Otro invalida la acción racional. Siguiendo esta línea de acción, todo encuentro en el ámbito de la comunicación, de acuerdo al escéptico, es irracional. El cínico, en cambio, niega al Otro desde el inicio; y, con ello, niega toda prioridad y encuentro argumentativo. El Otro deviene un medio para el cínico porque es la "afirmación del Poder del Sistema como fundamento de una razón que controla o gobierna a la razón estratégica como mediación de su propia realización (como Poder absoluto).” (Dussel, E.; y, Apel, K.-O. [2004], nota 16, p. 175). Es una mediación para su proyecto definido en la totalidad desde donde se gestiona la 'razón estratégica'.

Hoy en día, Trump o Bolsonaro son unos aparentes escépticos frente a la ética del discurso; sin embargo, frente a una filosofía de la liberación serían unos cínicos porque no solo 
niegan al Otro, sino que tampoco entran a la discusión como argumentantes dispuestos a ofrecer razones. Mandan con la fuerza, no de los argumentos, sino de la armas. Ese es el cinismo concreto del que hablamos, porque, además, su 'razón estratégica' reduce la argumentación a una mera negociación instrumental y, desde ahí, establece la moralidad del sistema vigente, finalmente dominador. Dice Dussel:

La filosofía de la liberación se enfrenta desde el inicio 'dentro' de una Totalidad (sistema o mundo) o se opone a la dominación de la razón cínica [...]. La filosofía de la liberación se enfrente a las 'artimañas' de una tal razón estratégica fundada en el Poder. Esto determina la 'arquitectónica' de la filosofía de la liberación. (Dussel, E.; y, Apel, K.-O. [2004], 176-177).

Apel no logra entrever que al argumentar empíricamente, ya se está dentro de la Totalidad, que se tiene ya como un presupuesto a la razón cínica; así que la "fundamentación última" de la ética del discurso tiene aún más profundidad porque el oponente escéptico puede ser un momento del cínico. El proceso de liberación comienza solo a partir de la manifestación del Otro. La razón cínica es explícitamente no ética desde la negación del Otro, como Otro. Ya no solo se trata de una responsabilidad a posteriori, como generalmente se le concibe desde el ámbito jurídico, sino a priori, porque desde antes el argumentante se hace cargo de la razón del Otro $^{2}$. La filosofía de la liberación no tiene como acceso al diálogo filosófico, ningún problema lingüístico, o discursivo, sino el de la praxis, debido a que al cínico no le interesa argumentar su posición, solo actúa en relación a su conveniencia ${ }^{3}$.La filosofía de la liberación desde sus primeras formulaciones parte de la articulación con los movimientos que exigen justicia. La reacción tan contundente de esta escuela surge de considerar que el escepticismo tiene relación con la funcionalidad del sistema vigente que está fundado en la razón cínica, en la razón del poder como dominio y no como servicio. Por eso el concepto del poder suele estar en términos negativos y la reacción a ello es siempre de rechazo. Por su parte, la filosofía de la liberación encuentra que el cínico parece manipular la situación según la cual, es mejor evitar que el escéptico no entre en la discusión con la ética del discurso porque sin él, desaparece la posibilidad del consenso argumental por medios racionales, no coercitivos. Y esta es la totalidad que es necesario desmantelar, porque la ética del discurso (y con ella toda la filosofía no crítica) parece justificar al cínico por el hecho de no considerarlo.

\footnotetext{
${ }^{2}$ Esto marca un problema complejo que Jonas propone como lo porvenir: "ex-post-facto por lo hecho, sino a la determinación de lo que se ha de hacer. [...] responsabilidad orientada al futuro.” Jonas, H. [1995], p.163 y ss.

${ }^{3}$ Se dice coloquialmente que EUA no tiene amigos, tiene intereses.
} 


\section{Lo "formal" de la segunda generación}

La ponencia presentada en Eichstätt, en abril de 1995, es de especial consideración porque es quizá el primer momento que Dussel describe su arquitectónica desarrollada después en la ética del 1998. Este autor comienza hablando de una "escisión originaria" donde Kant deja de lado la parte material de su ética. Es claro que su preocupación es la articulación entre la parte material y la formal. Si la tradición filosófica de occidente se había centrado en lo formal, deudora de la escolástica que posteriormente retomaría la filosofía analítica, para Apel la instancia del acto de comunicación era el punto de partida desde el cual se debía establecer el resto de los aspectos humanos. En cambio, para nuestro pensador el aspecto material es punto de partida y en cierta manera es el desde-donde se aplica, procedimentalmente, el formalismo de la moral. Con esto invierte la relación formal-material, pero además, las articula creativamente dejando espacio a otro aspecto, a saber, el de la factibilidad. Al menos con estos primeros aspectos daba por concluida, aunque sea de manera provisoria, una primera etapa de diálogo. Y no era poca cosa, porque a lo largo de la historia de la filosofía, se va diluyendo el ser humano hasta quedar solo una subjetividad incorpórea, estudiada por un formalismo aparentemente imposible de trascender. Así que el diálogo con Marx es fundamental, porque representa la recuperación antropológica, concreta, histórica, de dicha subjetividad. $\mathrm{Su}$ propuesta al diálogo, por tanto, establece que las partes material, formal y de factibilidad son condiciones necesarias pero no suficientes para una "fundamentación última" de la ética.

La ética del discurso ha sido una de las más rigurosas propuestas europeas en filosofía; se le llama la segunda Escuela de Frankfurt como herencia de la fundada por Adorno Horkheimer, Benjamin, entre otros. Sin embargo, Dussel le reprocha a esta segunda generación que no es tan crítica como la primera, dado que han olvidado lo más importante, a saber, la impronta de la crítica material de Marx. Por lo menos, dice:

La 'segunda generación' entonces, criticó a la primera por encontrarse todavía dentro de un paradigma solipsista-cognitivo a partir de la conciencia. Por el contrario, comenzar por la comunidad de comunicación y del lenguaje abría el nuevo ámbito de una pragmática, un horizonte intersubjetivo, ético y político, de las pretensiones de validez. (Dussel, E. [2007], p.341)

En el pensamiento falibilista de Apel, lo mismo que en Habermas, la prioridad es meramente formal sobre lo material, lo consensual sobre la corporalidad; pero no le dan importancia al hecho de que relegando dicha materialidad sufriente desaparece la víctima, como mayoría dominada (aquellas que de alguna manera fueron subsumidos por algún sistema material hegemónico, ya sea como raza, clase social, género, etc.) y excluida (aquellas que se quedaron como 'sobrantes' del sistema, imposibles de subsumir y no 'tener el privilegio' de ser 
explotados por el capital, o sin posibilidad de voz y voto en los procedimientos democráticos formales). Cuando en el proceso de argumentación desaparece la materialidad de la víctima, desaparece la posibilidad de contradicción performativa y solo queda la posibilidad de lograr la mejor consistencia formal. En la filosofía hay un subjetivismo extremo centrado en la razón, que piensa el mundo delimitado en el objeto "en sí", "en cuanto tal”, como si fuera mirado impersonalmente, lo que ya representa una contradicción desde los presupuestos mínimos.

A partir de estas consideraciones surge la víctima, entonces, como efecto no intencional de la totalidad; surge como intersubjetividad (no el sujeto aislado, sino la comunidad) simétrica (no necesariamente igual) anti-hegemónica (desde y frente a los sistemas hegemónicos). Solo a partir de la articulación entre lo material y lo formal se puede interpretar adecuadamente la realidad dolorosa de las víctimas. Por eso es posible definir así la universalidad del principio material, momento desde la cual se "aplica" a la dimensión procedimental, reinterpretando el sentido de las morales formales. Sólo entonces es posible integrar la factibilidad de las transformaciones en los procesos críticos, ya sean en tiempos de normalidad democrática, o excepcionalidad revolucionaria.

\section{Primera escisión metodológica: hacia el concepto de ecología}

De esta manera, vemos que una primera problemática que plantea la arquitectónica apeliana es la aceptación de no darle en acento debido a la materialidad, la vida humana en comunidad, al tomar en cuenta exclusivamente las condiciones de posibilidad universales de la validez moral de las decisiones. Dussel argumenta primero con una "tesis fundamental" de la ética de la liberación, luego con un juicio de hecho, no de valor, que deviene "criterio universal"; y, finalmente, el "principio universal". Lo material es un correlato de lo formal; de manera que la "tesis" de la ética de la liberación se enuncia como sigue:

el aspecto de 'contenido' de la ética, abstractamente (la reproducción de la vida del sujeto humano), tiene la universalidad propia y determina siempre materialmente todos los niveles de la moral formal. El aspecto 'formal' de la moral (lo recto, right, richtig), el nivel de la validez (Gültigkeit, validity) universal intersubjetiva, abstractamente, determina por su parte formalmente todos los niveles de la ética material. Se trata de una mutua, constitutiva y siempre presente codeterminación con diverso sentido (una 'material' y la otra 'formal'). (Dussel, E.; y, Apel, K.-O. [2004], 344).

Dussel no niega la importancia de la ética del discurso; al contrario: la afirma pero la integra a la ética de la liberación. Así nuestro autor "desamarra", si se me permite el término, el "nudo crítico" de la dualidad entre lo material y lo formal, mal discernido en otras filosofías; dado la tendencia del "subjetivismo" extremo del teorías liberales que niega la articulación con 
la economía; y, en el otro extremo, el "materialismo" de los marxismos radicales que ven en la política un mero tema adventicio y secundario del economicismo.

La designación misma de la crisis relacionada a la naturaleza ya es un problema inicial que debemos aclarar. Los sistema clasificatorios con lo que contamos pueden ser claros hasta cierto punto; después del cual, empiezan a ser confusos y se muestran insatisfactorios para dar respuestas específicas a problemas específicos. Justo destaca en ellos la obsesión por los aspectos parciales y no por el panorama completo, aún sistémico, para el mejor entendimiento del problema. Gómez-Heras habla de "argumentaciones filosóficas" para referirse al lugar de enunciación, desde el cual se evalúa un aspecto: el antropocéntrico, por ejemplo, que deja ver que todo reside en el humano y deja en un plano secundario a la naturaleza; el patocéntrico que vincula el mundo humano al sentir de los animales y plantas; el biocéntrico que podría abarcar a la ecología de los científicos naturales, en lo vivo; el fisiocéntrico, que podría referirse a la naturaleza, pasiva e infinita, como la consideran los economistas; y, el metafísico, donde pone a Hans Jonas, por la cuestión de la responsabilidad; finalmente, la teocéntrica. En su ensayo introductorio (Gómez-Heras, J. M. G. (coord.) (2002), p. 13-46) no aparece ninguna otra tradición cultural que se preocupe por la naturaleza.

Rozzi, en cambio, mucho más condescendiente con las distintas tradiciones latinoamericanas, considera no solo a los académicos en sus diversas tradiciones, sino al hecho de que todas ellas se han articulado a los distintos activistas, lo mismo pescadores que campesinos; es decir, amplía la praxis a una medida más extensiva de lo que ha sido el quehacer cotidiano en Latinoamérica, dado que el vínculo entre movimientos sociales, sociedad civil y Estado han estado imbricados en estos temas y de distintas maneras. Nos ofrece, por tanto, un excelente registro institucional de los grupos de trabajo que han funcionado desde hace varias décadas; y, algunos otros, como el de la decolonialidad, eminentemente de hispanos en Estados Unidos; o los varios esfuerzos por replicar las "comunidades de base" que dieron fisonomía propia a la "liberación". Por otra parte, incluye la muy extensa y añeja tradición sociológica latinoamericana (Rozzi, R. [2012], p. 9-32). Estos dos ejemplos nos dan una idea de que la preocupación teórica y práctica ha estado por mucho tiempo y ha sido abordada de muy diversas maneras; el espectro es enorme y de pronto, las posturas parecen dispersas e inconexas. No obstante, no se trata aquí de agotar el tema; aunque esto señala la dificultad de tener un solo diagnóstico científico para un problema que trasciende aún a las acciones estratégicas, los principios normativos y las instituciones responsables de producir, reproducir y acrecentar la vida humana en el largo plazo. Veamos la cuestión por partes. 
Bajo el apelativo de "ambientalismo" hay un sin fin de tendencias de las ciencias sociales, especialmente la política, dentro del ámbito liberal que tuvo un impulso decisivo en el Informe Brudtland. Otro tendencia es un cierto "ecologismo" que viene de las ciencias naturales y de la economía más centrada en un "marxismo estándar". Estas ciencias naturales se apoyan muy bien en los primeros resultados que vienen del llamado "club de Roma" y sus consecuentes estudios computacionales que lograron extrapolar datos disponibles para modelar escenarios pasados y futuros. No es difícil entrever que el "ambientalismo" tiene un fuerte sesgo hacia el liberalismo político tomado como su lugar de acceso a estas problemáticas. Esto nos lleva a pensar en el formalismo extremo vertido en las larguísimas, extenuantes e innecesarias reuniones en torno al Cambio Climático. El "ecologismo" ha tenido la virtud de ofrecer datos contundentes sobre el agotamiento y destrucción de la Tierra. La "crítica material" ha tenido más elementos sustanciales para cuestionar lo que hacen los líderes mundiales, porque se ha realizado desde las ciencias naturales. Así que de vez en cuando vemos que las dos tendencias se alían, en el caso de las grandes cumbres diplomáticas mundiales, o se contraponen, en las manifestaciones frente a catástrofes imprevisibles y mal gestionadas. En términos de la praxis, la primera más diplomática, la segunda más contestataria; pero las dos, francamente eurocéntricas. Y con esto queremos puntualizar que están dentro del ámbito moderno que considera la relación "hombre-naturaleza", como una dualidad antropológica insostenible, si se evalúa desde el monismo semita que adopta la filosofía dusseliana como punto de partida antropológico.

En este sentido, ¿en qué términos debe ser concebida una ecología en clave de la liberación $i$ Opino que debe recuperar los tres principios de la ética dusseliana porque, generalmente, la ecología solo hace referencia a situaciones acotadas en el funcionamiento biológico de la naturaleza; y, esto es solo un aspecto de muchas más. Empecemos con el primer discernimiento entre lo material y lo formal. No tiene sentido la "verdad" sin estar mediada por la discursividad "válida"; de hecho, no habría "verdad" sin consenso "válido". Si las matemáticas son "verdaderas" no es debido a la objetividad cuasi divina que algunas culturas le atribuyen, sino a su profundo y largo consenso válido intersubjetivo. Lo "válido" tiene referencia a lo "aceptable"; nadie discute, por tanto, que la suma de los cuadrados de los catetos sea igual al cuadrado de la hipotenusa, porque este resultado es producto no de una inteligencia monológica, sino de una deliberación larga, profunda y constante de una comunidad discursiva (que falsea, verifica, corrobora, comprueba, demuestra, corrige...) de expertos que llegó a establecer la "verdad" de este enunciado. De la misma manera, pero en sentido contrario, no 
existiría lo "válido" sino no hubiese un "objeto", real y concreto, sobre el cual deliberar. Una y otra cosa, son correlatos del mismo acto: sin uno, el otro ni siquiera tiene sentido.

En el caso concreto de la ecología, primero debemos distinguir que no se debe confundir el "contenido" de la acción material con la acción material misma: no se debe confundir mascar (verbo que denota la situación física) con comer (verbo que indica mediación para estar vivo); de la misma manera, no se debe confundir el acto específico de "encimar ladrillos", al panorama completo de "construir un casa": el acto meramente técnico puede ser el mismo, pero la mediación panorámica de todos actos articulados en torno al objeto es siempre para la vida. Así que entre lo material y lo formal, hay una articulación circular: "la verdad condiciona materialmente a la validez, y la validez determina formalmente a la verdad.” (Dussel, E. [2001], 77). El aspecto material (de contenido) de la ecología condiciona (en el sentido de ser sustrato físico desde-el-cual) la manera de alcanzar la "aceptabilidad" de los actos; simultáneamente la deliberación ecológica, cuyo resultado en la validez de los actos determina (en el sentido de dar forma, de establecer actos consecuentes de lo formal a lo material) la manera de "captar" la realidad; de "actualizarse" en lo real.

\section{Verdad (material) y validez (formal)}

Tenemos, entonces, dos aspectos de un mismo "acto ecológico"; ya no uno (eminentemente material, "fisiocéntrico", como registramos antes) como la ecología tradicional evalúa su tarea. Ahora lo material y lo formal nos ayudan a discernir problemas más diáfanamente. Tomemos el caso de la capa de ozono. El artículo que registró las emisiones (la "verdad" de la investigación científica en comunidades muy cerradas de expertos) de ciertas sustancias químicas (los CFC) que eran arrojadas a la atmósfera fue publicado en 1972, por Rowland y Molina. Hasta quince años después, las múltiples e incansables deliberaciones, a varios niveles del gobierno norteamericano, fue dado como "válida" la tesis según la cual estas sustancias eran nocivas para la capa de la estratósfera, agotada en ciertos momentos del año, especialmente en el hemisferio sur terrestre. Resultado de ello, fue la implementación institucional del llamado Protocolo de Montreal, hacia 1987-1989, para comenzar la reducción de los gases que causaban la pérdida de la capa de ozono atmosférico, indispensable para la vida de la Tierra (justo el principio material de la ética).

No tiene sentido ético el descubrimiento científico de las emisiones que causan el agotamiento de la capa de ozono, a nivel material, sin su articulación a nivel formal de la aceptabilidad de más de 150 países que suscribieron, y que siguen ratificando, el protocolo. Dada su "aceptabilidad", y consecuentemente su "incuestionabilidad", se dice que es el acuerdo 
ecológico más exitoso. Pero, ¿cómo convencer al escéptico sobre un problema que tiene 150 años, que se encuentra a 30 kilómetros de la superficie terrestre, que proviene de un gas cuyas propiedades son imperceptibles? Los sociedades de los países industriales usaban cotidianamente solventes, refrigerantes y aerosoles que contenían estas sustancias nocivas. El detalle técnico que hizo posible no cambiar el estilo de vida de los involucrados (el aspecto material) fue la posibilidad de cambiar las sustancias prohibiendo las anteriores. Estamos justo en el nivel de la factibilidad ecológica. Es el cumplimiento de la verdad válida y posible de una modernidad que se ocasiona un problema con solución. Pero quizá sea el único caso así, porque el problema actual con los incendios del Amazonas se debe evaluar de otra manera; sobre todo, porque partimos de la invalidez de las decisiones locales (del gobierno actual de Bolsonaro) enfrentadas a las decisiones de las instituciones internacionales. El acento se encuentra en lo formal que delibera sobre la verdad de su objeto: la selva como "pulmón del planeta", cuya "verdad" fue negada por el gobierno brasileño en la ONU.

La manera de poner a prueba la falibilidad de los argumentos del cínico, como decíamos al principio, determina la voluntad general (como esencia material del poder político) del consenso internacional. No todos interpretan el mismo hecho (la "verdad"). Por un lado, el presidente de Francia, Macron, asume como propia la responsabilidad de la selva gestionando recursos para apoyar; y, por otro lado, el presidente brasileño, Bolsonaro, condiciona dicho apoyo. La deliberación ecológica da como resultado la invalidez de las decisiones, dado que los dos deliberan desde una cierta colonialidad del poder, uno más global y el otro más local y subordinado a los intereses de los Estados Unidos, pero excluyendo a los habitantes milenarios de la selva, a los pueblos originarios. Y no solo eso, las causas se remontan a la no-verdad de las acciones tomadas unilateralmente, sobre todo de la agroindustria y la ganadería, en tanto incapaz de abastecer de alimentos al país, de producir con técnicas tradicionales, y dar empleo en los mismos lugares donde se produce y consume. El resultado es una desafortunada imposibilidad de cumplir con la producción, reproducción y acrecentamiento de la vida humana en comunidad, principio material crítico.

\section{Criterios y principios}

El criterio es una operación intelectiva que hace referencia al establecimiento de una escisión mínima para que algo, real y concreto, pueda ser pensado; es una crisis que reduce lo complejo y lo transforma en simple. El discernimiento de la ética, bajo la forma de criterios enunciados junto con principio deónticos (de obligación, de deber ser), pone el acento en la vida humana en comunidad, al establecer las condiciones de su permanencia en la misma trama 
de la vida cósmica a todos los niveles. Un discernimiento mal efectuado puede conducir a dilemas falsos, frecuentemente presentados como universales. Por eso, el orden del razonamiento que llamamos "arquitectónica" debe partir de la realidad, como juicio de hecho para conducir a la fundamentación (hacia la esencia) de los principios en la ética y que, en la política, nombramos como la "normatividad de la política", a diferencia del "estratégico" y el "institucional".

El "criterio universal de verdad" señala que el sujeto debe discernir una mediación para la vida, que puede ser una "norma, acto, institución o eticidad". (Dussel, E.; y, Apel, K.-O. [2004], p. 345). La elección de algo-para establece una finalidad binaria (vida-muerte) que depende del concepto de la verdad. De frente a la filosofía analítica, Dussel argumenta que la pérdida del significado lingüístico remplaza a la realidad física, al cosmos físico, quedándose en la mera consistencia formal de los enunciados. No obstante, recupera (a) la verdad, como consenso intersubjetivo; (b) la inteligibilidad, como la condición de la comunicación; (c) la significatividad, como lo comprensible desde un marco de sentido común; y (d) el sentido de la coherencia, como articulación de acción y su significado. La realidad, por tanto, es el "lugar" de la trama viviente que constituye como "realidad objetiva" actualizándola como "verdad" en términos de su gestión propia. Los territorios indios, los hábitats, como nos sugiere Rozzi, son la "verdad", en tanto "arraigo" cultural milenario.

[el arraigo] se deja llevar más bien por el mundo de vida compartida que lo sostiene y renace desde él como una actividad comunitaria. [...]. De hecho no hay subjetividad y objetividad sino más bien un nudo de relaciones donde el sujeto humano aprende que lo decisivo no es el dominio de lo otro. Es la conciencia de la copertenencia y de la religación de todo lo real. (Fornet-Betacourt, R. [2004], 78).

Al ser despojados de su tierra, los indios quedan en la intemperie, desprovistos de la materialidad cultural frente a la humilladora actitud de la "razón cínica". Todo acto humano está en referencia última en este criterio, dado que "hacer" supone el contenido porque se hace "para" la vida; y la vida humana es tanto un modo de realidad como un criterio de verdad. Además, la verdad es “actualidad [que] depende del 'acceso' que el viviente, desde su vida y para su vida, tenga de lo real.” (Dussel, E. [2001], p. 104). El sujeto se actualiza en lo real dentro de su circunstancia material (como inconscientemente la respiración del oxígeno, o la comida que elije ingerir) más inmediata. La vida humana es, materialmente, un "modo de realidad", es actualización constante de la totalidad de su medio, siendo él mismo parte de él. No se trata de un sujeto enfrentado a un objeto, sino de un viviente humano dentro de una realidad cuantitativamente más grande y previo (el planeta Tierra), significativamente condicionante de un mundo (en tanto naturaleza) y determinado culturalmente por la materia. (Dussel, E. [2011], 
esquema 4.1). No es un argumento a favor del antropocentrismo (como varios ecologismos reprochan), sino el único "modo de realidad" que, teniendo a cargo su vida, puede fallar en su discernimiento y elegir una mediación que lo "saque" del circuito de la vida. Ni se establece jerarquías de inteligencia, teleológicas o de significancia, dado que lo humano no es un fin en sí mismo, sino que es un locus enuntiationis desde donde se establecen todos los fines posibles.

\section{La víctima como comunidad de vida}

No existe un sistema perfecto; así que, empíricamente, siempre tendrá efectos negativos no intencionales. "para la condición humana finita tal tipo de acabamiento es imposible. Esto permite deducir que no siendo perfecto son inevitables, y más cuando se tiene en cuenta la incertidumbre de toda decisión humana, efectos negativos." (Dussel, E. [2006], [11.01]). Las víctimas son quienes sufren dichos efectos negativos, pero ellos mismos son un efecto negativo. Entre la totalidad (lo "dado") y la exterioridad (lo "por darse", el desarrollo de la dialéctica como movimiento) exige una deconstrucción como proceso negativo, crítico. Dice Dussel:

El juicio ético de la razón práctica crítica negativa es trans-sistémica, y si el sistema de la "comprensión del ser" (en el sentido heideggeriano) es lo ontológico, sería entonces pre, o trans-ontológico: un juicio que procede desde la realidad de la vida negada de las víctimas, en referencia a la totalidad ontológica del sistema de eticidad dado. (Dussel, E. [1998], [206]).

La realidad negada de la víctima exige una transformación del sistema que ya no es capaz de poner las condiciones para el acrecentamiento de la vida humana en comunidad. Y no se trata solo de la negación de la negación, como tradicionalmente desde la perspectiva hegeliana se concebía, sino de un movimiento dialéctico crítico, o analéctico, como sigue:

El movimiento completo no es negación (de la esclavitud) de la negación (del esclavo como ser humano negado), sino que es antecedido por: 1) la afirmación de la libertad posible del esclavo en un sistema futuro (más allá del mundo presente, este mundo, como momento ético o trans-ontológico de enfrentar la totalidad vigente como totalidad injusta), desde donde se puede 2) negar la esclavitud óntica empírica 3) que niega la dignidad humana del esclavo. (Dussel, E. [2016], [11.33])

En la primera semana, los medios de comunicación no dejaban claro si la preocupación por los incendios del Amazonas era más por el $20 \%$ de oxígeno que ya no podrán recuperar las sociedades urbanas del planeta, más que por los miembros de las comunidades indias (los pueblos originarios) que hicieron posible durante los últimos milenios la preservación de la selva. En el quehacer cotidiano de la filosofía de la liberación se debe tener mucha claridad que no hay uno sin el otro: el biocidio es un suicidio. (Téllez, E. [2020]). La "sabanización" de la selva ha dejado a los indios en la intemperie absoluta, en la Tierra devastada, pero que solo adquiere sentido a través de la indignidad comunidad de vida. Solo desde la comunidad de 
víctimas es posible hacer un juicio crítico que haga el diagnóstico adecuado del sistema positivo que ofrezca una explicación del "mal originario", como causa de la víctima. En este sentido, entre otras más, podríamos advertir las siguientes acepciones de la víctima:

(a) es negatividad, (dado que el punto de partida es positivo) como lo "Otro negado" (en la exterioridad) que "lo dado" (en la totalidad), es alteridad absoluta del Otro, como Otro y no como lo mismo, que el sistema, no como "diferente", sino como "distinto": lo "distinto" de lo "uno";

(b) es, en concreto, necesitante, en el sentido de ser "inacabado", como "falta-de", siguiendo la crítica de la dialéctica sartriana, como un "ser" que se pone enfrente (contrario a la interioridad de la negatividad y a favor de su ulterior desenvolvimiento), en tanto proyecto futuro, adviniente;

(c) es efecto no intencional, en relación directa con la factibilidad, en tanto que es inevitable (imposible de evitar) e involuntario (imposible dentro del marco de la voluntad de vida) e indeseable (porque no se puede desear su existencia como efecto que se "escapa de control" sin ser previsto);

(d) es el "lugar" empírico de la patología del sistema, como resultado, cercano o remoto (como las generaciones futuras), de la totalización del sistema (como fetichismo que se vuelve autónomo y contrario a la vida) que exige su transformación;

(e) es indicativo de la ineficacia del sistema de eticidad, de su no-verdad, no-validez y no factibilidad, es un fenómeno (aparece frente a-, como "muestra") de la inoperancia del sistema de eticidad; y,

(f) es un descubrimiento empírico, en todo caso a posteriori contrario al a priori de la razón, y por ello el origen material (de contenido) primero es el dolor de la corporalidad: no es "algo pensado" en la proxemia, sino "alguien sentido" en la proximidad, categoría primera de la filosofía de la liberación. (Dussel, E. [2011], [2.1]).

g) es “criticidad”, como fuente de crítica y contenido de toda posibilidad futura, es decir, que señala la manera en que el sistema debe ser pensado para ser transformado eventualmente.

En el sentido negativo de este nivel material, el reconocimiento concreto del juicio de hecho, según el cual existen las víctimas, deviene "criterio crítico" (o criterio de criticidad). El "criterio negativo, material o de contenido, es el hecho mismo de la imposibilidad de reproducir la vida de la víctima." (Dussel, E. [1998], [270]). El cinismo de la espectacularidad de los incendios y la torpe reacción de los políticos eclipsó la centralidad de la víctima, del indio, como comunidad de vida en su hábitat del que forman parte consustancial. Pero además, 
nulamente señalada la causa fundamental, no la fenoménica de la agroindustria o la ganadería, sino aquella que hace posible todos estos aspectos: la tasa de ganancia, como criterio necroeconómico. El hecho contundente de que exista la víctima viene de la imperfección del sistema, dado que empíricamente es imposible la perfección y siendo inevitables, se vuelve inevitable también la crítica. "Para las víctimas el futuro es el tiempo de la esperanza; deben luchar para estar mejor, porque en el presente sufre la negación, en la que no es posible vivir. La crítica es el comienzo de la lucha" (Dussel, E. [1998], [273]) Hay dos aspectos en el criterio crítico; por una parte, el positivo, plantea que es un reconocimiento del Otro absoluto, en tanto vulnerabilidad viviente, en toda su extrañeza (como totalmente Otro) y lejanía (en las futuras generaciones aún no existentes en el aquí y ahora, tema por excelencia de la ecología clásica). Por otra parte, es el hecho de la imposibilidad del acrecentamiento cualitativo de la vida de la víctima. Su existencia es refutación material de la "verdad" del sistema que la origina. Por eso, todo sistema empírico, que produce inevitablemente víctimas, es criticable por contener la "noverdad" del biocidio.

El criterio de validez, procedimental o formal "es la pretensión de alcanzar la intersubjetividad actual acerca de enunciados veritativos, como acuerdos logrados racionalmente por una comunidad.” (Dussel, E. [1998], [152]). La verdad tiene referencia a lo material, mientras que lo válido hace referencia a lo procedimental. La actualización de lo real (verdad) es siempre intersubjetiva; y, la actualización de la intersubjetividad (validez) tiene referencia a un presupuesto veritativo. La verdad se alcanza con el consenso, mientras que lo válido se alcanza con lo verdadero. Pero ambas, verdad y validez, son históricas, falibles. El criterio de "validez crítica" se refiere a la participación simétrica de los afectados; previamente excluidos y que constituyen como no-válido, y por lo mismo no aceptable, los consensos de la comunidad hegemónica. Desde hace cinco siglos los indios son excluidos de todo consenso; de ahí que todo Estado sea ilegítimo, pero también todas las instituciones transnacionales, privadas y públicas. La exclusión misma de las decisiones las vuelve inválidas. No se trata de que los excluidos simplemente sea incluidos en la totalidad hegemónica de comunicación; sino, de crear una nueva comunidad consensual con nuevas condiciones formales de validación en una participación simétrica de afectados. El problema de la devastación del Amazonas no se acaba dando empleo formal a los campesinos y pueblos originarios; sino discutiendo la mejor manera de convivir con la naturaleza en el muy largo plazo (para los próximos milenios). Del autorreconocimiento de la indignidad debido a la imposibilidad de vivir, surge entonces una 
comunidad crítica de víctimas que se explica el origen de su exclusión (como crítica negativa) y anticipa alternativas futuras (como crítica positiva).

El discernimiento de lo factible trata la distinción entre lo posible y lo imposible. De esto depende la realización, eficacia, u operabilidad del sistema de eticidad, norma, acto, etc. El resultado binario, vida-muerte, no deja ver la infinidad de mediaciones que suponen los estrechos límites de lo vivo; para lo cual la factibilidad cobra un sentido nuevo, una vez que es articulada con los otros aspectos en esta ética. Sin este criterio los debates se diluyen en problemáticas radicales y caen en relativismos insalvables. El acento se pone en las circunstancias materiales y por lo tanto, en la contingencia de los actos. Aunque este criterio claramente hace referencia a no dejar de considerar las leyes de la naturaleza, es decir la relación humano-naturaleza, es que remite directamente a la parte material en el hecho de hacer posible lo que posibilita la vida; de manera que esto deja ver la suficiencia en la articulación de los criterios en términos de la pretensión de bondad (en la ética), o de la pretensión de justicia (en la política). Dice Hinkelammert,

La racionalidad que responde a la irracionalidad de lo racionalizado solo puede ser la racionalidad de la vida de todos, incluida la naturaleza, porque únicamente hay lugar para la vida humana si existe una naturaleza que la haga posible. Y esta racionalidad de la vida nada más se puede fundar en la solidaridad entre todos los seres humano. Se trata de una solidaridad necesaria, pero no por eso inevitable. (Hinkelammert, F. [2013], p. 353.).

El criterio crítico-factible de toda "transformación" hace referencia a la posibilidad de liberación de la comunidad de víctimas. "Porque hay víctimas con cierta capacidad de transformación se puede y se debe luchar para negar la negación antihumana del dolor de las víctimas, intolerable para una conciencia ético-crítica.” (Dussel, E. [1998], [387]). La dignidad de la víctima es ya exigencia de posibilidad y obligación ${ }^{4}$. Este criterio es lo más complejo, dado que imbrica una cantidad de temas de distintos niveles y perspectivas que es necesario considerar como, el juicio, la capacidad y las condiciones de la transformación posible. Estos tres temas hacen alusión al dinamismo propio de las circunstancias materiales y formales; y no solo eso, sino que señalan que la contingencia puede ser determinante para la consecución de los fines propuestos.

\footnotetext{
${ }^{4}$ La dignidad se es, es lo "ya dado", en tanto no producido; no se tiene, como algo adventicio a "lo dado". Ver: Téllez, E. [2015].
} 


\section{Comentarios finales}

Vivimos bajo el asedio del cínico con tendencia suicida, que no asume la voluntad de vivir perdiendo el sentido del deber y, consecuentemente, decide por la no permanencia de la vida en la Tierra. Hoy en día el hecho, cuantitativamente contundente, de vivir "a crédito", de acuerdo a la contabilidad de nuestra "huella ecológica" global, es la apuesta de una moral por la justificación del sibarita fugaz en contra de las generaciones futuras perennemente, como postulado. Así que todo en la ética tiene sentido solo a través de la vida humana, como condición absoluta. La ética de la liberación es una ética de la vida que apuesta a ser la teoría necesaria para el activista indignado por la injusticia global que se manifiesta hoy en todo el mundo. Se alimenta justamente de la praxis que se pone en "estado de riesgo", como Berta Cáceres y tantas otras mártires de las generaciones futuras, exponiéndose a la dominación; y que pretende articularse ofreciendo orientación mínima a los actos estratégicos y a las instituciones (cada vez más pasivas a pesar de haber sido concebidas en términos de la sustentabilidad, como la PNUMA, EPA, las múltiples “cumbres", "protocolos” y demás) dentro de la contingencia de las circunstancias.

Es decir, el actor político y las instituciones políticas deberían de ocuparse cada vez más de manera apremiante de esta dimensión ecológica, porque es el momento en que, positivamente, acontece la producción, reproducción y desarrollo de la vida humana (contenido del principio material de la política), y, negativamente, se enfrenta al evitar la extinción de la vida en el planeta Tierra. (Dussel, E. [2009], [319]).

Para resumir, podemos sintetizar de manera extrema los siguientes enunciados basados en los principios normativos de la acción, que se muestran como "deber ser", a nivel de la fundamentación de la ética material dusseliana:

a) En el nivel material trata del reconocimiento de algo (mediación) para la vida (como deber de querer vivir). El nivel crítico trata la no-mediación de algo para vida; o, la mediación de algo para la muerte: criterio necrofílico por excelencia como el capital donde todo biocidio es suicidio.

b) En el nivel formal trata del reconocimiento de alguien (la víctima) para aceptar la razón del Otro (deber de querer escuchar). El nivel crítico trata el no-atender la interpelación del Otro: todo homicidio es suicidio.

c) En el nivel de factibilidad trata del reconocimiento de la posibilidad de los actos (deber de poder imaginar). El nivel crítico trata la imposibilidad del acrecentamiento cualitativo de la comunidad de víctimas creando mediaciones (principios, instituciones) nuevas que lo permitan. Toda esperanza posibilita el futuro. 
Hablamos entonces de la verdad válida posible que permite positivamente la vida humana en comunidad; y, negativamente, de la no-verdad in-válida e imposible del sistema hegemónico debe ser (en tanto principio normativo) superada. Entiéndase que la también mediación aceptable y operativa debe ser una fórmula (que no por ello reduccionista, o un facilismo inaplicable) que apoye la acción estratégica en lo político, aunque la concepción profunda de ello le requiere paciencia al político profesional, o al activista. Puede haber una mediación que no cumpla con los otros aspectos (inaceptable y inoperante) y no tendría la pretensión del "acto bueno" que buscamos. Lo mismo se cumple para los otros dos aspectos. La liberación ecológica atraviesa todos y cada de estos momentos, mutuamente determinantes. Así que la pretensión de bondad en la ética ecológica debe considerar esta articulación para permanecer en la trama vital, amenazada hoy por múltiples factores y de muy difícil discernimiento. De ahí, la importancia de considerar en el centro de la discusión esta arquitectónica.

Todo ello define la ecología con una mayor amplitud que como un simple tema, políticamente correcto hoy, en la academia. La construcción de un nuevo orden requiere de la paciencia de un anciano para la interpretación teórica, de vitalidad juvenil en la praxis política y de la imaginación infinita de un artista.

\section{REFERENCIAS}

Apel, K.-O. [1999], Estudios Éticos, México: Fontanamara.

Dussel, E. [1998], Ética de la liberación. En la edad de la globalización y la exclusión, Madrid: Trotta.

Dussel, E. [2001], Hacia una filosofía política crítica, Bilbao: Desclée de Brouwer.

Dussel, E.; y, Apel, K.-O. [2004], Ética del discurso y ética de la liberación, Madrid: Trotta.

Dussel, E. [2006], 20 Tesis de política, México: Siglo XXI-CREFAL.

Dussel, E. [2007], Materiales para una política de la liberación, México: UANL y Plaza y Valdez.

Dussel, E. [2009], Política de la liberación. Arquitectónica, volumen II, Madrid: Trotta.

Dussel, E. [2011], Filosofía de la liberación, México: FCE.

Dussel, E. [2016], 14 tesis de ética. Hacia la esencia del pensamiento crítico, Madrid: Trotta.

Fornet-Betacourt, R. [2004], Crítica intercultural de la filosofía latinoamericana actual, Madrid: Trotta.

Gómez-Heras, J. M. G. (coord.) (2002), Ética en la frontera. Medio Ambiente. Ciencia y técnica. Economía y empresa. Información y democracia, Madrid: Biblioteca Nueva. 
Hinkelammert, F. \& Mora, H. (2013). Hacia una economía para la vida. Preludio a una segunda crítica de la economía política ( $4^{\mathrm{a}}$ ed.). México: UMSNH y EUNA.

Jonas, H. (1995), El principio de responsabilidad. Ensayo de una ética para la civilización tecnológica, Barcelona: Herder.

Mills, F. [2018], Enrique Dussel's Liberation Ethics. An Introduction, USA: PalgraveMacmillan.

Rozzi, R. "Filosofía Ambiental Sudamericana: Raíces Amerindias Ancestrales y ramas académicas emergentes”, en: Enviromental Ethics, vol. 34, número S4, p. 9-32.

Téllez, E. [2015], “El criterio de los valores”, Cuadernos de ética, vol. 30, año 2015.

Téllez, E. [2020], “33.1. La voluntad de vida”, en Dussel, E. (ed.), Política de la liberación, volumen III, Madrid: Trotta. 